\title{
A Review on the Kinetics of Iron Ore Reduction by Hydrogen
}

\author{
Aidin Heidari ${ }^{1}$, Niusha Niknahad ${ }^{2}$, Mikko Iljana ${ }^{1}\left(\mathbb{D}\right.$ and Timo Fabritius ${ }^{1, *(\mathbb{D})}$ \\ 1 Process Metallurgy Research Unit, University of Oulu, 90570 Oulu, Finland; aidin.heidari@oulu.fi (A.H.); \\ mikko.iljana@oulu.fi (M.I.) \\ 2 Department of Materials Science and Engineering, Sharif University of Technology, Tehran 1458889694, Iran; \\ n.niknahad97@sharif.ir \\ * Correspondence: timo.fabritius@oulu.fi
}

\section{check for}

updates

Citation: Heidari, A.; Niknahad, N.; Iljana, M.; Fabritius, T. A Review on the Kinetics of Iron Ore Reduction by Hydrogen. Materials 2021, 14, 7540. https://doi.org/10.3390/ma14247540

Academic Editor: Johannes Schenk

Received: 20 October 2021

Accepted: 25 November 2021

Published: 9 December 2021

Publisher's Note: MDPI stays neutral with regard to jurisdictional claims in published maps and institutional affiliations.

Copyright: (c) 2021 by the authors. Licensee MDPI, Basel, Switzerland. This article is an open access article distributed under the terms and conditions of the Creative Commons Attribution (CC BY) license (https:/ / creativecommons.org/licenses/by/ $4.0 /)$.

\begin{abstract}
A clean energy revolution is occurring across the world. As iron and steelmaking have a tremendous impact on the amount of $\mathrm{CO}_{2}$ emissions, there is an increasing attraction towards improving the green footprint of iron and steel production. Among reducing agents, hydrogen has shown a great potential to be replaced with fossil fuels and to decarbonize the steelmaking processes. Although hydrogen is in great supply on earth, extracting pure $\mathrm{H}_{2}$ from its compound is costly. Therefore, it is crucial to calculate the partial pressure of $\mathrm{H}_{2}$ with the aid of reduction reaction kinetics to limit the costs. This review summarizes the studies of critical parameters to determine the kinetics of reduction. The variables considered were temperature, iron ore type (magnetite, hematite, goethite), $\mathrm{H}_{2}$ / CO ratio, porosity, flow rate, the concentration of diluent $\left(\mathrm{He}, \mathrm{Ar}, \mathrm{N}_{2}\right)$, gas utility, annealing before reduction, and pressure. In fact, increasing temperature, $\mathrm{H}_{2} / \mathrm{CO}$ ratio, hydrogen flow rate and hematite percentage in feed leads to a higher reduction rate. In addition, the controlling kinetics models and the impact of the mentioned parameters on them investigated and compared, concluding chemical reaction at the interfaces and diffusion of hydrogen through the iron oxide particle are the most common kinetics controlling models.
\end{abstract}

Keywords: hydrogen; green steelmaking; kinetics; ironmaking; iron ore; reduction

\section{Introduction}

Nowadays, carbon dioxide emissions have become one of the most important environmental concerns, the consequences of which include global warming. Approximately $7 \%$ of the total carbon dioxide produced in the world belongs to the iron and steel industries [1]. On average, 1.9 tons of carbon dioxide are emitted per ton of crude steel produced. Hence, the iron and steel industries are trying to reduce carbon dioxide emissions and make the iron production process more environmental-friendly by developing new technologies [2]. Among the technologies being developed in this regard, hydrogen as a reducing agent [3-6], carbon capture and storage (CCS) [7,8], carbon capture and utilization (CCU) $[9,10]$, biomass as a reducing agent $[11,12]$, and electrolysis can be mentioned [13-15].

Hydrogen such as carbon monoxide can reduce iron oxides and produces water vapor instead of carbon dioxide. At the moment, a mixture of hydrogen and carbon monoxide is used for iron ore reduction in the direct reduction plants by reforming the natural gas. Hence, it seems by performing some modifications and considering the technical and economical essentials, direct reduction plants can use hydrogen as the only reducing agent in the future. Furthermore, hydrogen can be produced from renewable sources such as biomass that makes the process more environmentally friendly. Therefore, the reduction of iron ore with hydrogen has attracted much attention in recent years [16,17].

In order to minimize the consumption of energy and other elements, it is crucial to study the kinetics of reduction reactions. As there are several reactions that are occurring simultaneously, the kinetics of reduction is very complex [18]. 
Due to the working temperature, there are different ways to obtain metallic iron from hematite. Reactions can be a chain of single reaction, single and double reaction or a triple reaction as the following [19]: $\left(\mathrm{Fe}_{2} \mathrm{O}_{3}, \mathrm{Fe}_{3} \mathrm{O}_{4}\right.$ and $\mathrm{FeO}$ corresponds to hematite, magnetite and wüstite, respectively).

$$
\begin{array}{cc}
\mathrm{Fe}_{2} \mathrm{O}_{3} \rightarrow \mathrm{Fe}_{3} \mathrm{O}_{4} \rightarrow \mathrm{Fe} & \text { for } \mathrm{T}<450{ }^{\circ} \mathrm{C} \\
\mathrm{Fe}_{2} \mathrm{O}_{3} \rightarrow \mathrm{Fe}_{3} \mathrm{O}_{4} \rightarrow \mathrm{Fe}_{\mathrm{x}} \mathrm{O}+\mathrm{Fe} \rightarrow \mathrm{Fe} & \text { for } 450{ }^{\circ} \mathrm{C}<\mathrm{T}<570{ }^{\circ} \mathrm{C} \\
\mathrm{Fe}_{2} \mathrm{O}_{3} \rightarrow \mathrm{Fe}_{3} \mathrm{O}_{4} \rightarrow \mathrm{FeO} \rightarrow \mathrm{Fe} & \text { for } \mathrm{T}>570{ }^{\circ} \mathrm{C}
\end{array}
$$

Due to its nature, the kinetics of iron ore reduction by hydrogen can be classified as gas-solid reactions. There are usually three kinetic-controlling mechanisms of diffusion through the gas film layer, diffusion through the ash layer, and the chemical reaction for these reactions (Figure 1). Hence, five steps can be considered for iron ore reduction by hydrogen $[3,20,21]$ :

1. Diffusion of hydrogen through the film surrounding the iron ore particle.

2. Diffusion of hydrogen through the blanket of ash (consisting of the final product, i.e., iron, and gangue such as silica, alumina, etc.) to the surface of the unreacted iron ore.

3. Chemical reaction of hydrogen with iron ore at this reaction surface.

4. Diffusion of the gaseous product $\left(\mathrm{H}_{2} \mathrm{O}\right)$ through the ash back to the exterior surface of the particle.

5. Diffusion of the gaseous product $\left(\mathrm{H}_{2} \mathrm{O}\right)$ through the gas film back to the main body of fluid $[20,21]$.

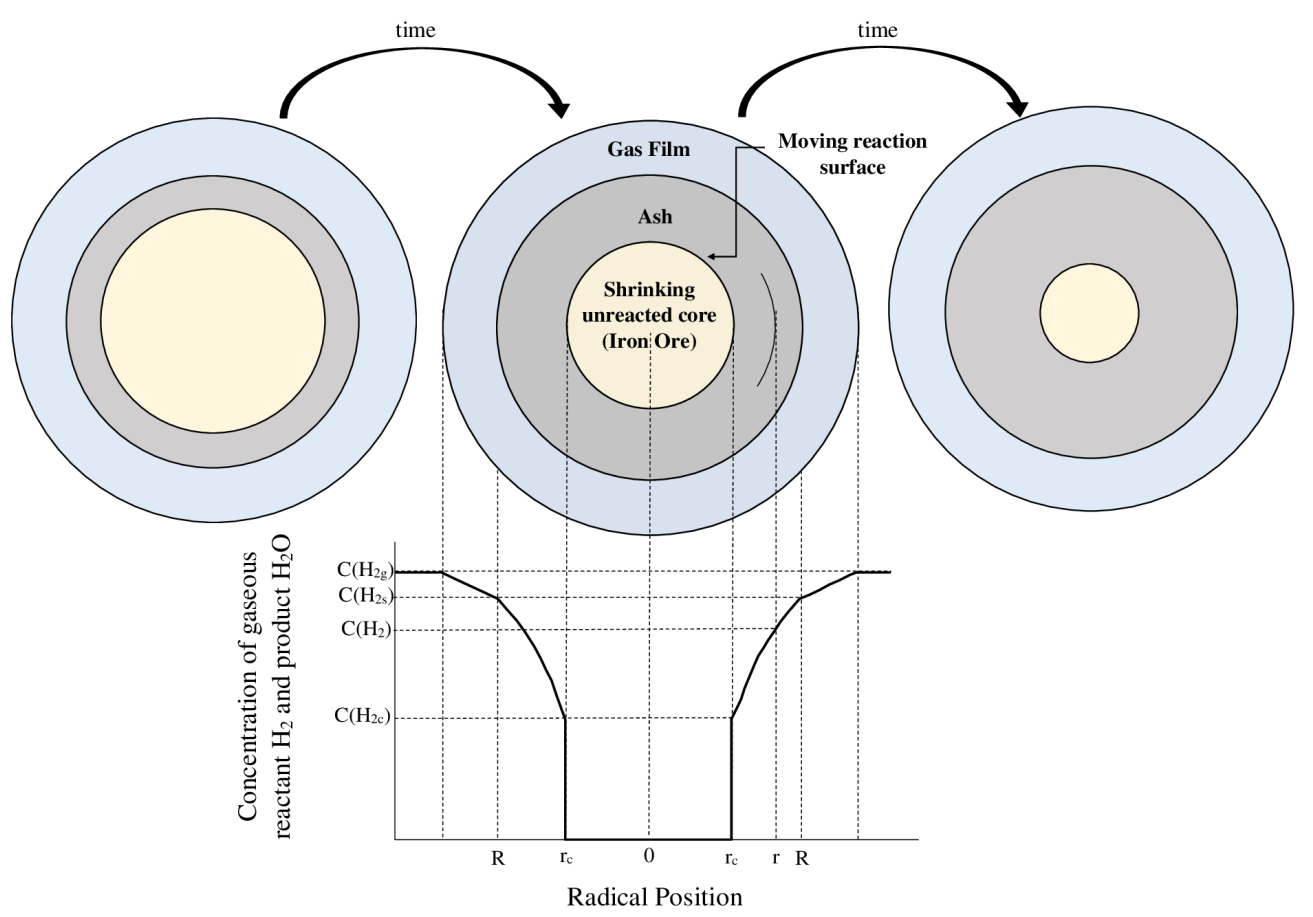

Figure 1. Schematic shrinking core model modified after [21] "modified".

- Control by diffusion through the gas film

$$
\frac{t}{\tau}=X, \tau=\frac{\rho R}{3 b k_{g} C_{g}}
$$


- Control by diffusion through the ash layer

$$
\frac{t}{\tau}=1-3(1-X)^{\frac{2}{3}}+2(1-x) \tau=\frac{\rho R^{2}}{6 b D_{e} C_{g}}
$$

- Chemical reaction control

$$
\frac{t}{\tau}=1-(1-X)^{\frac{1}{3}}, \tau=\frac{\rho R}{b k^{\prime \prime} C_{g}}
$$

where " $t$ " is time, " $X$ " is fraction of reacted material (reaction fraction), and " $\tau$ " is the reaction completion time. " $\rho$ " is the density of solid reactant, " $R$ " is the radius of the particle, " $b$ " is the stoichiometric coefficient of the solid reactant when the stoichiometric coefficient of the gaseous reactant is equal to 1 , " $\mathrm{k}_{\mathrm{g}}$ " is the mass transfer coefficient. " $\mathrm{C}_{\mathrm{g}}$ " is the concentration of the gaseous reactant in the main body of fluid, " $D_{\mathrm{e}}$ " is the diffusion coefficient, and " $k$ "' is the rate constant of the reaction.

For the high gas velocity, it can be assumed that film diffusion does not offer any resistance to transfer and reaction. Thus, film resistance can safely be ignored [20,21].

It can be determined from Equations (5) and (6) that the reduction time is proportional to $R^{2}$ and $R$ for the diffusion through ash layer and chemical reaction respectively. So, by plotting log (time) vs. log (particle radius), the slope of the line can determine the kinetics controlling mechanism [22].

Figure 2 illustrates that chemical reaction and ash diffusion are both controlling factors, but diffusion limits the rate of reduction mainly near the end. Although several parameters such as temperature, porosity, mineralogy, etc. have an effect on the kinetics of reduction, it seems that the two mentioned mechanisms are the major kinetics controlling mechanisms for the iron reduction by a gaseous reductant [22]. Some researchers also considered the mechanisms based on nucleation and growth.

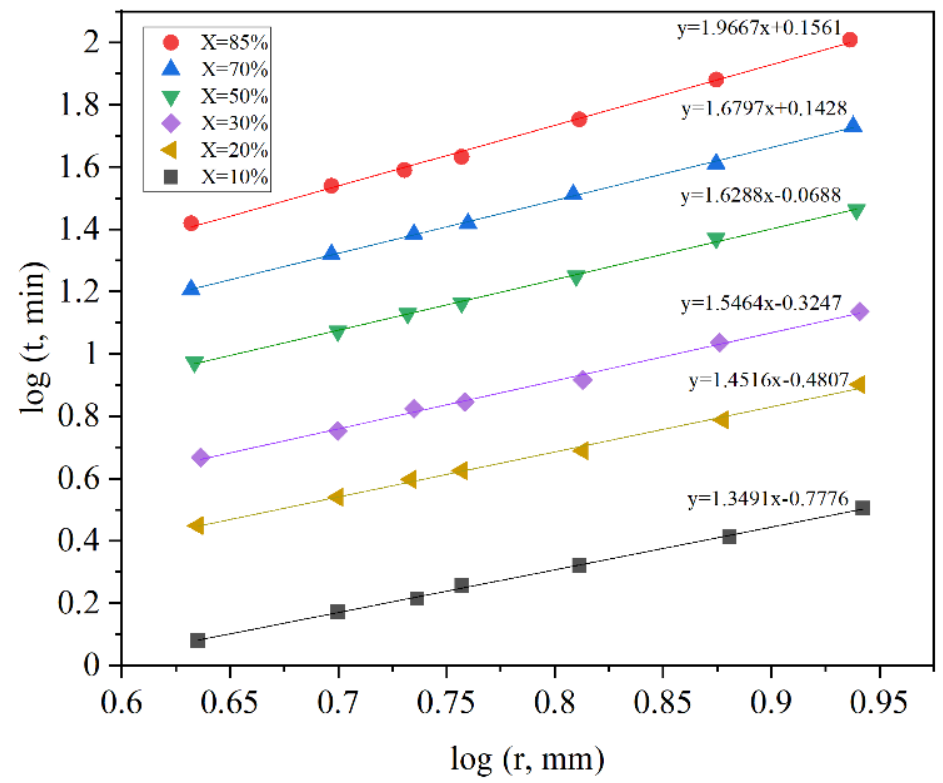

Figure 2. Plot of log (time) vs. log (particle size) for different reaction fractions [22] "modified".

In this research, the studies that have determined the effect of different parameters on the kinetics of reduction by experiment, modeling and simulation are reviewed. 


\section{Effect of Different Parameters on the Kinetics of Reduction}

\subsection{Effect of Temperature}

The effect of temperature on the kinetics of reaction was investigated from two points of view. The dependence of rate constant is explained by the Arrhenius equation (Equation (7)), where " $k$ " is the rate constant, " $A$ " is the frequency factor, which is related to the frequency of collisions and the orientation of a favorable collision probability, " $E_{a}$ " is the activation energy, " $R$ " is the ideal gas constant, and " $T$ " is the temperature in Kelvin.

$$
k=A \exp \frac{-E_{a}}{R T}
$$

The diffusion coefficient in solids also is a function of temperature and is expressed by the Arrhenius equation (Equation (8)). In this equation, " $D_{0}$ " is the maximal diffusion coefficient, " $E_{a}$ " is the activation energy of diffusion, " $R$ " is the ideal gas constant, and " $T$ " is the temperature in Kelvin.

$$
D=D_{0} \exp \frac{-E_{a}}{R T}
$$

Hence, in both cases, the rate of reduction will increase exponentially by increasing the temperature.

Barde et al. investigated the reduction rate in the range of $800-1000{ }^{\circ} \mathrm{C}$ and found that the increase in reduction rate by increasing the temperature is more effective at the early stages of the reduction [23]. Valipour et al., presented a mathematical model of the reduction of iron ore by a gas mixture of hydrogen, water vapor, carbon monoxide, and carbon dioxide. The results confirmed the positive dependence of temperature on the reduction rate. They found that the increase in diffusivity and reaction rate are the causes of this phenomenon [24]. Tsay et al. also achieved similar results in their experiments and mathematical model. Their results also showed that the higher diffusivity of hydrogen at higher temperatures can overcome the larger gas transport resistance of the larger pellets [25]. Baolin et al. found that for temperatures higher than $600{ }^{\circ} \mathrm{C}$, the reduction of $\mathrm{Fe}_{2} \mathrm{O}_{3}$ to $\mathrm{Fe}_{3} \mathrm{O}_{4}$ is very fast and as a result, the effect of temperature on the reduction rate is not considerable. However, for the reduction of $\mathrm{Fe}_{3} \mathrm{O}_{4}$ to $\mathrm{FeO}$ the temperature becomes more effective and increasing the reduction rate can be obviously detected. By the further reduction of $\mathrm{FeO}$ to $\mathrm{Fe}$, the effect of temperature becomes negligible again [19]. Wagner et al. reached similar results. Their experiments showed that the effect of temperature on the reduction rate is more intensive for the reduction temperatures lower than $800{ }^{\circ} \mathrm{C}$ (Figure 3) [26]. Choi et al., achieved the $80 \%$ and $100 \%$ reduction at 5 and $10 \mathrm{~s}$, respectively, at $1100{ }^{\circ} \mathrm{C}$ [27] while the $80 \%$ was obtained in the study by Fruehan et al. in about $500 \mathrm{~s}$ at $600{ }^{\circ} \mathrm{C}$, both in the $100 \% \mathrm{H}_{2}$ flow [28].

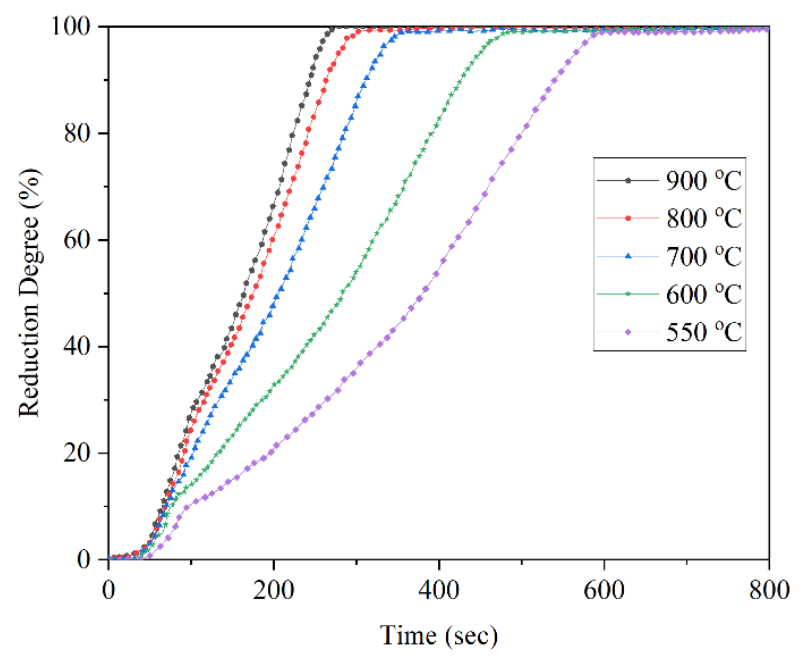

Figure 3. Effect of temperature on the reduction rate $\left(100 \% \mathrm{H}_{2}\right)[26]$ "modified". 


\subsection{Effect of $\mathrm{H}_{2} / \mathrm{CO}$ Ratio}

The ratio of hydrogen to carbon monoxide in the reducing gas is of great importance to control the reduction rate. The equilibrium diagram of iron oxides, hydrogen and carbon monoxide (Figure 4) shows the equilibrium gas composition to reduce iron ore. Thermodynamic calculations have shown that $\mathrm{CO}$ has a higher reducing ability at lower temperatures, whereas reduction by $\mathrm{H}_{2}$ is more thermodynamically stable at higher temperatures [29]. From a kinetic point of view, due to the atomic size of hydrogen and its high diffusivity, $\mathrm{H}_{2}$ is a faster reductant in comparison with $\mathrm{CO}$ at temperatures above $850^{\circ} \mathrm{C}$ [30]. Hence, increasing the temperature both thermodynamically and kinetically improves the hydrogen reduction.

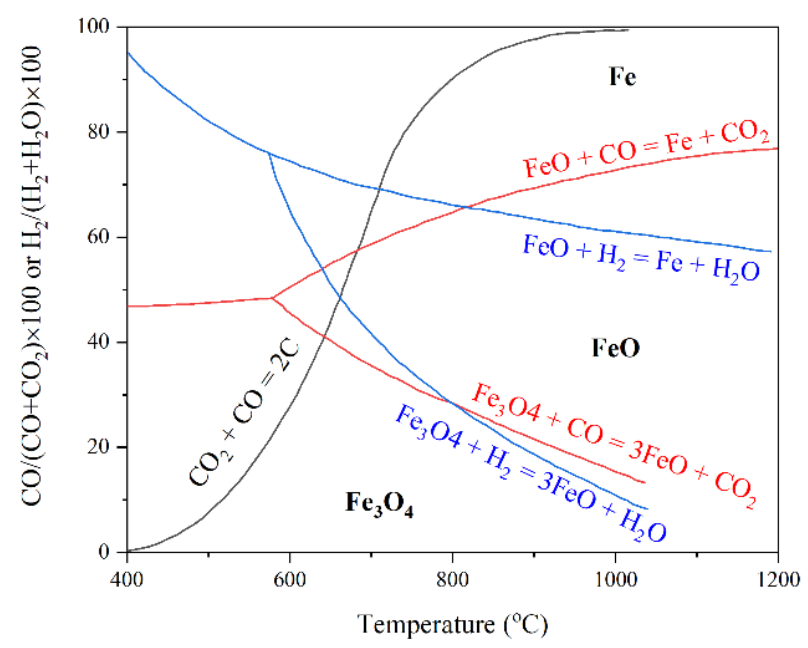

Figure 4. Gas composition in equilibrium with iron and iron oxide phases as a function of temperature [29] "modified".

Zuo et al. investigated the effect of mixture gas composition on reduction degree and compared the experimental data with a mathematical model. In this study, increasing the reaction rate with the higher hydrogen content in three temperatures $\left(800{ }^{\circ} \mathrm{C}, 900{ }^{\circ} \mathrm{C}\right.$ and $1000{ }^{\circ} \mathrm{C}$ ) is reported (Figure 5). This occurs due to the higher reducing and diffusing capacities of hydrogen compared with CO at temperatures above $890^{\circ} \mathrm{C}$. Furthermore, as the temperature increases the rise of reduction degree for the higher $\mathrm{H}_{2}$ content decreases, which is also approved by Kemppainen et al. [31,32]. In addition, the suggested mathematical model presents an acceptable linear relationship with the reduction degree (over 93\%). The only exception is for the cases at $1000{ }^{\circ} \mathrm{C}$, which is justified due to the deformation of pellets at high temperatures [32].

In another study, Yi et al., studied the reduction rate of iron ore pellets at 850,900 , 950,1000 and $1050{ }^{\circ} \mathrm{C}$ with varying $\mathrm{H}_{2} / \mathrm{CO}$ proportions from 0.4 to 2.6. By increasing the ratio range from 0.4 to 1.6, a superior reduction rate was observed. On the other hand, changing the ratio range from 1.6 to 2.6 has little effect on the reduction rate. This indicates the importance of choosing the right ratio of $\mathrm{H}_{2} / \mathrm{CO}$ and not simply raising the amount of hydrogen content [33]. Abdelrahim et al., found that the pellets reduced in $\mathrm{CO}_{-} \mathrm{CO}_{2}-$ $\mathrm{H}_{2}-\mathrm{H}_{2} \mathrm{O}-\mathrm{N}_{2}$ have more porosity and surface area than that reduced in $\mathrm{CO}-\mathrm{CO}_{2}-\mathrm{N}_{2}$ [34]. Formation of carbide, slower reduction, and reaching the complete reduction at higher temperatures, for the hematite reduction by $\mathrm{CO}$ in comparison with $\mathrm{H}_{2}$ was reported by Abu Tahari et al. [35]. 

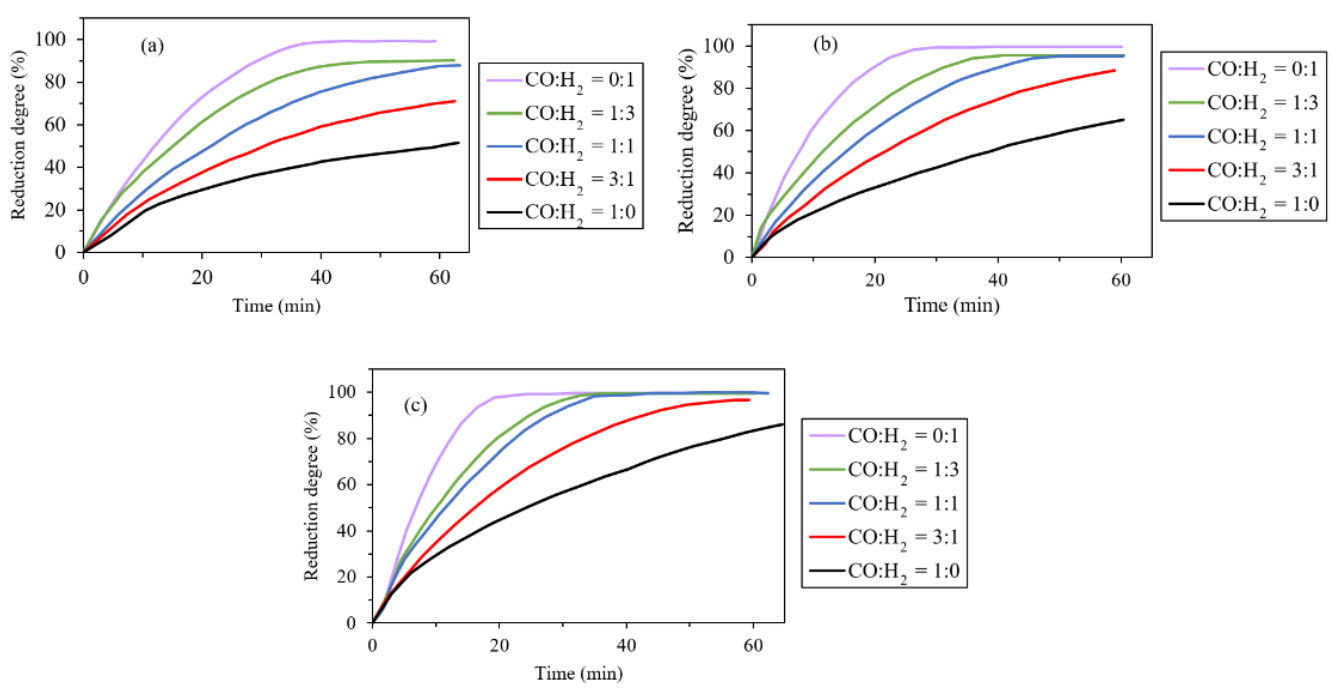

Figure 5. Change of reduction degree with reducing time: (a) $800^{\circ} \mathrm{C}$; (b) $900{ }^{\circ} \mathrm{C}$; (c) $1000^{\circ} \mathrm{C}[32]$ "modified".

El-Geassy observed the role of hydrogen in the $\mathrm{H}_{2} / \mathrm{CO}$ gas mixture for reducing wüstite. In this experiment, wüstite was reduced up to $25 \%$. The next step was substituting hydrogen with nitrogen for a while and then the reduction continued in pure $\mathrm{CO}$ atmosphere. The result of this experiment compared with reducing the wüstite with pure $\mathrm{CO}$ from the beginning. Figure 6 designates that using $\mathrm{H}_{2} / \mathrm{CO}$ instead of pure $\mathrm{CO}$ accelerates the reduction rate. The main cause of this observation is the nucleating of iron on the wüstite surface in the $\mathrm{H}_{2}$ atmosphere. The addition of $\mathrm{H}_{2}$ to $\mathrm{CO}$ facilitates the nucleation of iron on the surface of the wüstite and also accelerates the growth of iron grains [36].

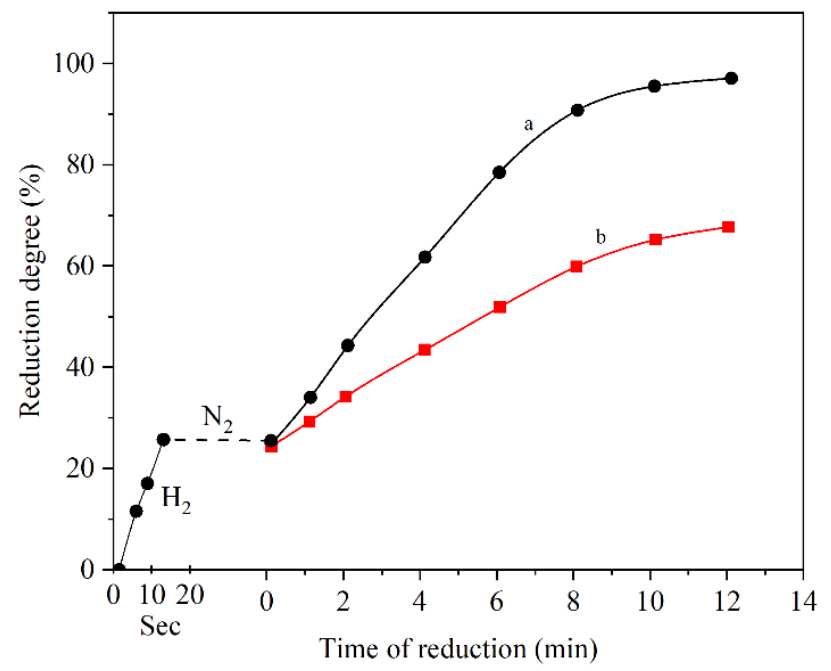

Figure 6. Reduction of wüstite at $1000{ }^{\circ} \mathrm{C}$ in (a) $\mathrm{H}_{2}$ followed by $\mathrm{CO}$; (b) pure $\mathrm{CO}$ [36] "modified".

\subsection{Effect of Hydrogen Flow Rate}

The hydrogen inlet flow rate can specify the overall concentration of hydrogen in the reactive structure. Barde et al. studied the reduction of iron-silica Magnetically Stabilized Porous Structure (MSPS) by hydrogen. Figure 7 shows the steam generation for 1.5 and 2 standard liters per minute hydrogen inlet flow rate at $800{ }^{\circ} \mathrm{C}$. It was observed that a higher inlet flow rate results in higher steam generation at the early stages of the reaction. However, the two graphs are not notably different at the later stages [23]. Kawasaki et al. realized that there is a critical gas velocity, which is specified experimentally at different temperatures. The superficial gas velocity considered 0.01 to $0.03 \mathrm{~mol} /\left(\mathrm{min} . \mathrm{cm}^{3}\right)$. Below critical gas velocity, the gas flow rate controls the rate of the reaction [37]. 


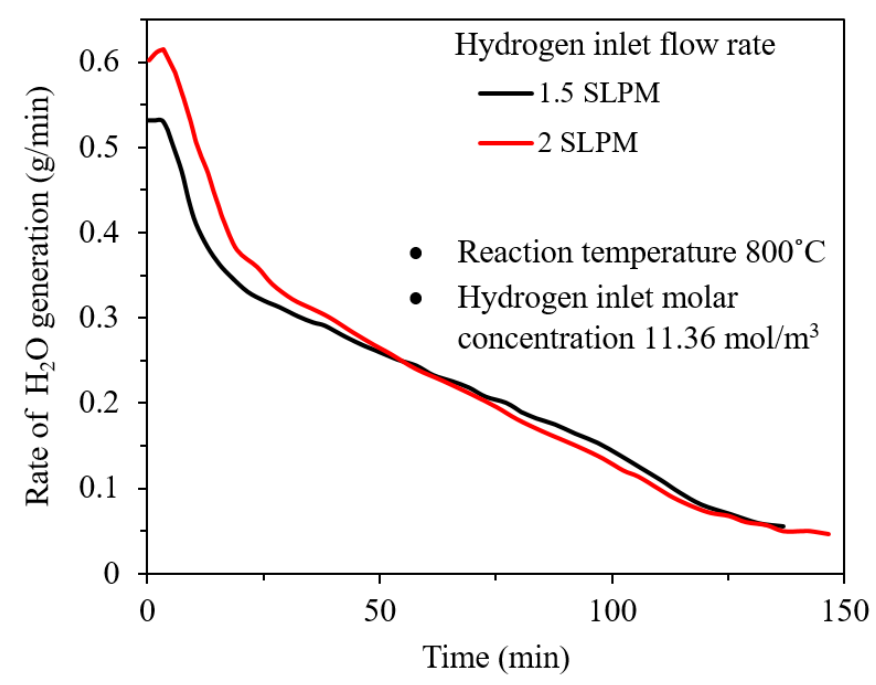

Figure 7. Rate of steam generation during the reduction for a hydrogen inlet flow rate of 1.5 and 2.0 SLPM at $800{ }^{\circ} \mathrm{C}[23]$ "modified".

Kulia et al. investigated the effect of various hydrogen flow rates $(0.1,0.2,0.3,0.4$, and $0.5 \mathrm{~L} / \mathrm{min}$ ) on fractional reduction of magnetite ore at $900^{\circ} \mathrm{C}$ and $1 \mathrm{~atm}$ pressure. The result of the experiments shows an increase in fractional reduction as the flow rate raises from 0.1 to $0.4 \mathrm{~L} / \mathrm{min}$ (Figure 8 ). In addition, the flow rates above $0.4 \mathrm{~L} / \mathrm{min}$ are not noticeably different from the others. Therefore, $0.4 \mathrm{~L} / \mathrm{min}$ was considered as the optimum hydrogen flow rate [38].

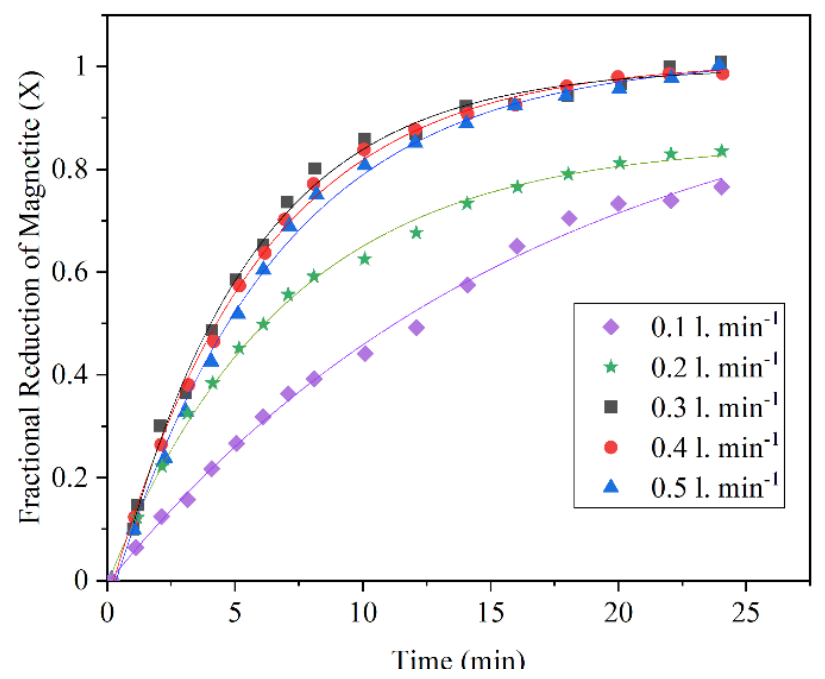

Figure 8. Fractional reduction of magnetite vs. time plot for the reduction of magnetite ore fines at different flow rates at $900{ }^{\circ} \mathrm{C}[38]$ "modified".

Ohmi et al., evaluate the effect of hydrogen flow rate, which was diluted by $\mathrm{N}_{2} / \mathrm{H}_{2} \mathrm{O}$ on the mixed control plots. The conclusion is similar to [32]. Furthermore, resistance for gaseous diffusion around a pellet increases with the decrease in gas flow rate due to experiments $[39,40]$.

\subsection{Effect of Mineralogy}

Edstrom et al., compared hydrogen reduction of hematite with magnetite. As illustrated in Figure 9, the reduction of hematite by hydrogen is faster than the reduction of magnetite, especially at higher temperatures. This is because of the hard and dense shell of magnetite, which causes lower diffusivity [41]. Furthermore, due to the higher density of 
hematite $\left(5.260 \mathrm{~g} / \mathrm{cm}^{3}\right)$ in comparison with magnetite $\left(5.175 \mathrm{~g} / \mathrm{cm}^{3}\right)$, during the reduction of hematite to magnetite, some microcracks form because of the volume change. The formed cracks work as porosities and make the diffusion of gas easier (Figure 10) [42,43]. Heikkilä et al. compared the reduction behavior of iron ore pellets, sinter, and lump ore at different temperatures. The lump ore showed the lowest reduction rate at all temperatures due to its low porosity and surface area. At the lower temperatures, (lower than $800{ }^{\circ} \mathrm{C}$ ) the pellet reacted faster, but at the higher temperatures, the reduction rate of the sinter was higher (Figure 11). It was found that it is because of the higher initial magnetite content in the composition of the sintered sample, which reduces slowly at low temperatures [44].

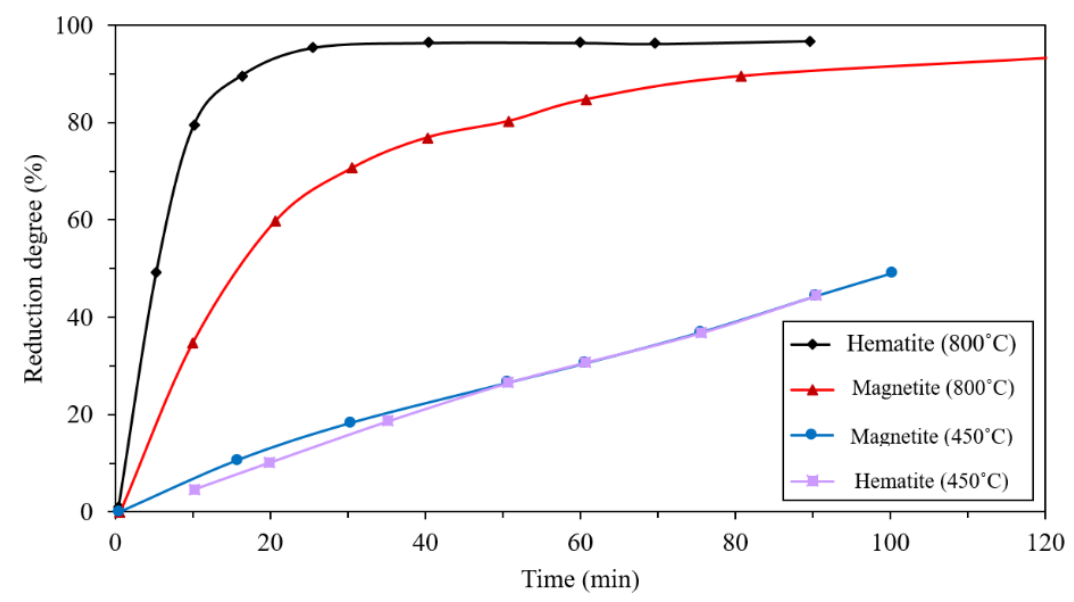

Figure 9. Comparison of hematite and magnetite reduction at the two temperatures $450{ }^{\circ} \mathrm{C}$ and $800{ }^{\circ} \mathrm{C}[41]$ "modified".
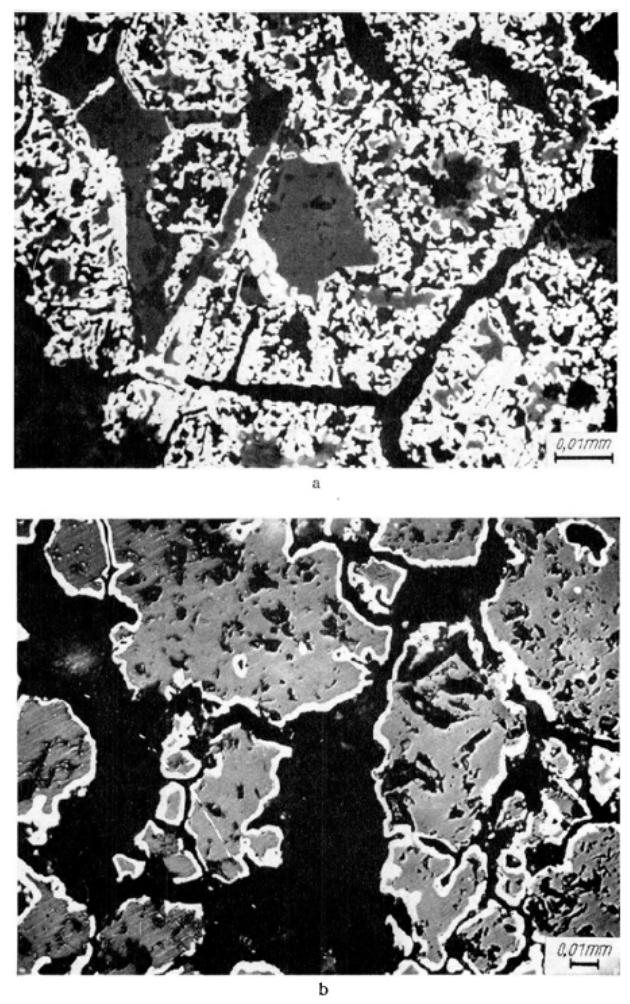

Figure 10. The SEM images of (a) reduced hematite; (b) reduced magnetite [43]. 

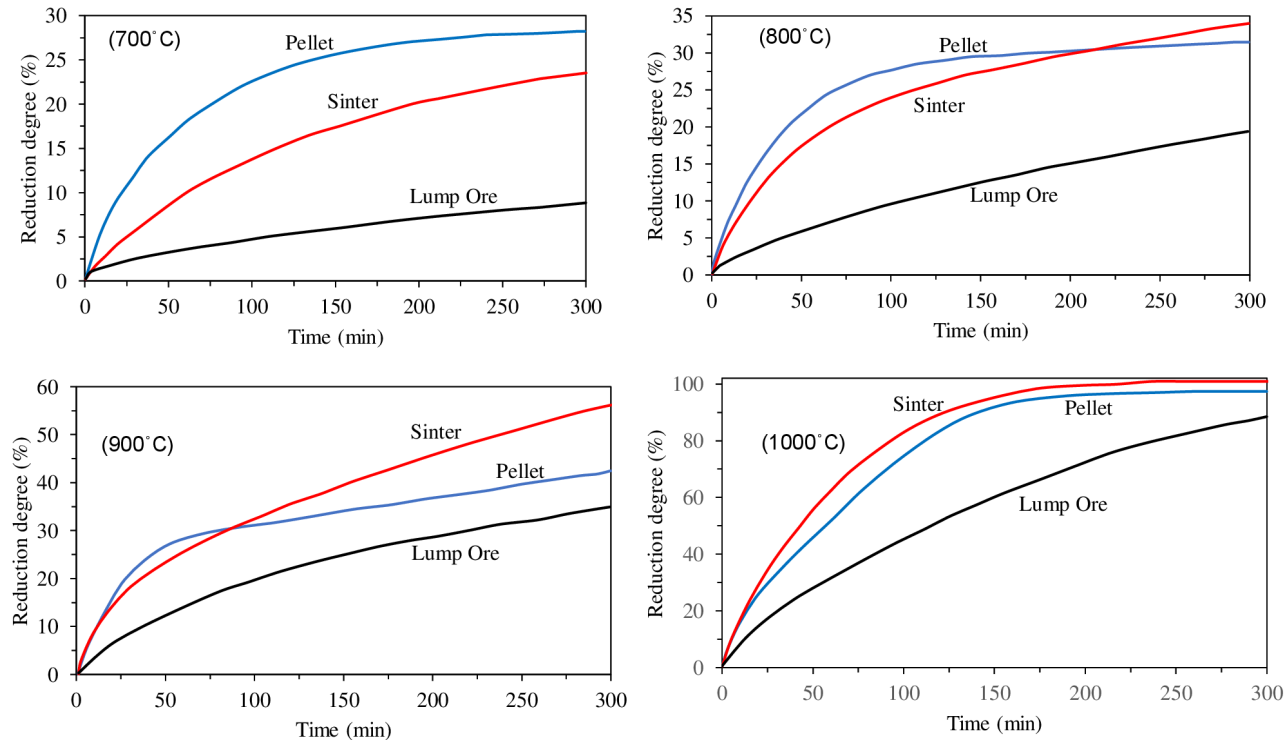

Figure 11. Reduction degree as a function of time for iron ore pellet, sinter, and lump ore at 700, 800, 900, and $1000{ }^{\circ} \mathrm{C}[44]$ "modified".

Oxy-hydroxides such as goethite have shown high reducibility due to the high surface area caused by water loss [45].

Fruehan et al. found that if iron oxides are converted to magnetite and kept in the same form as magnetite for a few minutes before reduction to iron, which can be called "annealing", it causes a decrease in the degree of reduction especially at higher temperatures and lower hydrogen pressures (Figure 12) [28].

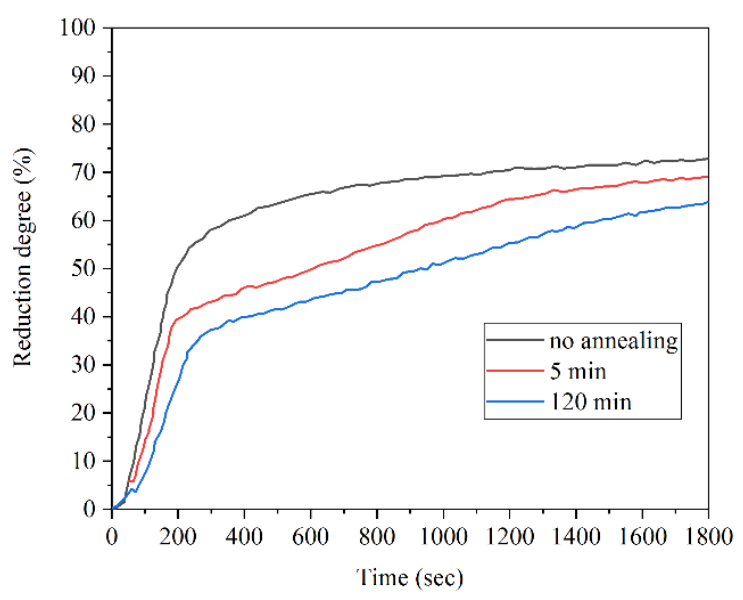

Figure 12. Effect of annealing on the reduction of Wabush ore at $800{ }^{\circ} \mathrm{C}$ in $60 \% \mathrm{H}_{2}$ [28] "modified".

\subsection{Effect of Particle Size}

Zhang et al. found that by increasing the pellet size from 5.5 to $8.5 \mathrm{~mm}$, the reduction rate decreases steadily due to the shorter diffusion distance (Figure 13) [46]. Similar results were obtained by researchers [47-49], which were approved by mathematical modeling [24]. At low reduction temperatures, particle size is not an effective parameter and other ratelimiting parameters become more important [50]. Hou et al. studied the reduction of particle sizes from 0.025 to $0.2 \mathrm{~mm}$. The results showed that for the particle sizes smaller than $0.045 \mathrm{~mm}$ the dependence of reduction rate on particle size is not considerable, because the internal diffusion resistance is neglectable for particle size below $0.045 \mathrm{~mm}$ [19]. 


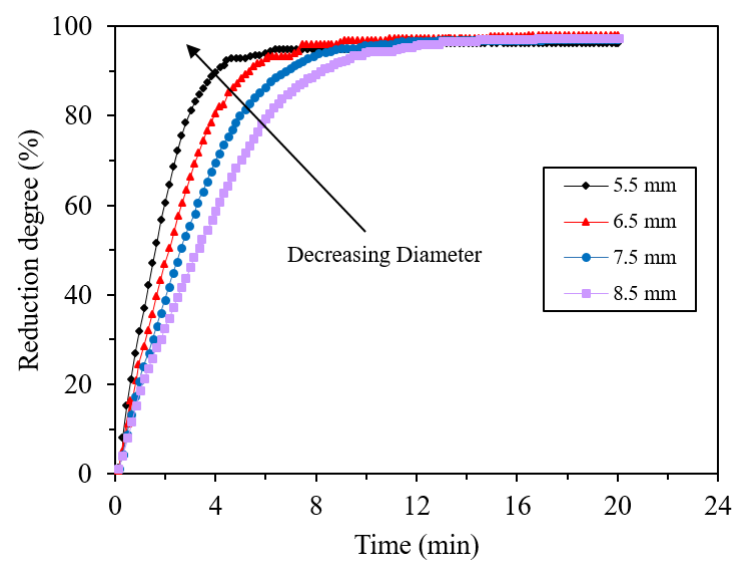

Figure 13. Dependence of reduction degree on reduction time of oxidized spherical pellets with different diameters. Data obtained at $1070{ }^{\circ} \mathrm{C}$ in flowing $\mathrm{H}_{2}$ gas [46] "modified".

Wagner et al. investigated the hydrogen reduction of three samples of coarse powder (P1), sintered piece (S1), and nanopowder (N1). Although the specific area for N1 and S1 is higher than P1 due to their smaller particle size, the reduction of the P1 sample was faster than the two other samples. By investigation of the reduced samples' morphology, it became clear that $\mathrm{S} 1$ and $\mathrm{N} 1$ samples became compact and lost most of their porosities after reduction while the P1 sample retains its porosity after the reduction (Figure 14) [26].

(a)

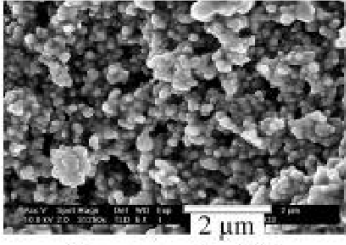

Coarse powder $(\mathrm{P} 1)$

(b)

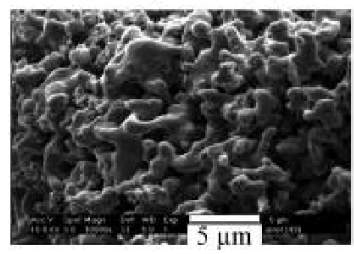

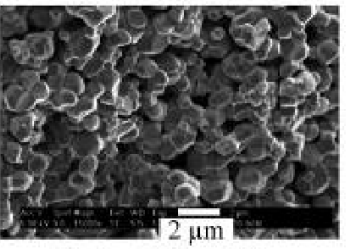

Sintered piece (S1)

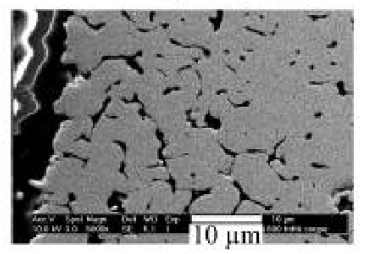

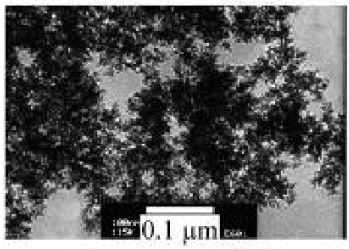

Nanopowder (N1)

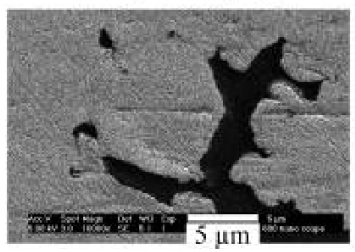

Figure 14. Cross-sections of the different samples (a) before and (b) after reduction [26].

\subsection{Effect of Impurities}

The effect of impurities on the reduction of iron ore by hydrogen is mostly similar to the reduction of carbon monoxide. Qie et al. found that by increasing the temperature and hydrogen concentration, the formation of the phases such as $\mathrm{MgFe}_{2} \mathrm{O}_{4}$ and $\mathrm{Fe}_{\mathrm{x}} \mathrm{Si}_{\mathrm{y}} \mathrm{O}_{4}$ become faster, which increases the resistance of interfacial chemical reaction during the reduction. Higher contents of $\mathrm{CaO}, \mathrm{SiO}_{2}$, and $\mathrm{MgO}$ can be found in larger particles which leads to the formation of cracks and accelerate the reduction of wüstite [51]. Alumina forms $\mathrm{Fe}_{3} \mathrm{O}_{4}-\mathrm{FeAl}_{2} \mathrm{O}_{4}$ solution by diffusion of $\mathrm{Al}^{3+}$ from wüstite, which enriches the hercynite content in the solution at the reaction interface. Further reduction of $\mathrm{Fe}_{3} \mathrm{O}_{4}-\mathrm{FeAl}_{2} \mathrm{O}_{4}$ solution leads to the formation of micro-cracks, which increases the rate of reduction (Figure 15) [52]. However, in another research, Teplov found that the presence of $\mathrm{Al}_{2} \mathrm{O}_{3}$ and $\mathrm{MgO}$ decreases the rate of magnetite reduction by hydrogen and the effect of $\mathrm{Al}_{2} \mathrm{O}_{3}$ is higher than $\mathrm{MgO}$ [47]. The presence of $\mathrm{TiO}_{2}$ of more than $0.5 \mathrm{wt} . \%$ increases the rate of reduction at the beginning of the reduction process due to the formation of cracks in pellets (Figure 16) [53]. 


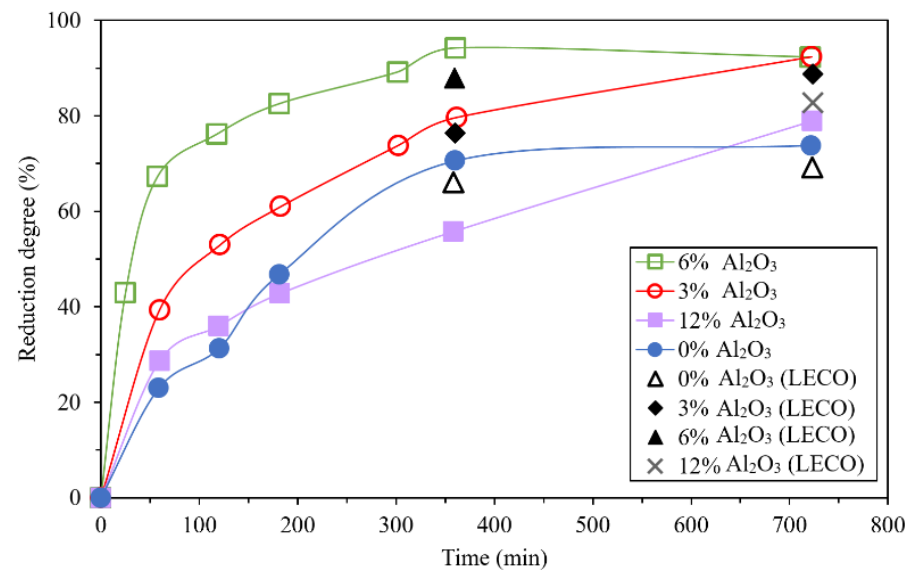

Figure 15. Effect of alumina content on reduction of $\mathrm{Fe}_{3} \mathrm{O}_{4}-\mathrm{Al}_{2} \mathrm{O}_{3}$ system at $850{ }^{\circ} \mathrm{C}$ by $\mathrm{CO}-\mathrm{CO}_{2}$ gas mixture (80\% CO) [52] "modified".

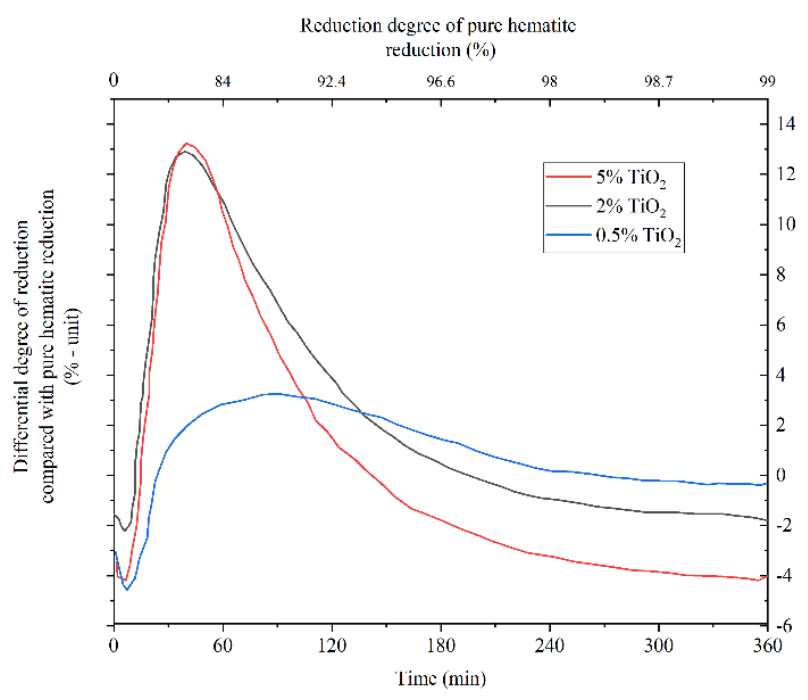

Figure 16. Effect of titanium dioxide on reduction of hematite. The curves show the difference from the reduction curve of pure hematite. The grade of reduction for pure hematite can be read from the secondary $x$-axis at the top of the figure [53] "modified".

\subsection{Apparent Activation Energy}

Activation energy is the minimum energy required to perform a chemical reaction, or in other words, the energy required to overcome a potential barrier. As mentioned earlier, the dependence of constant rate on the activation energy is expressed by the Arrhenius equation. In the case of complex reactions, the calculated activation energy is actually the average of all elementary steps. However, for an elementary reaction, a spectrum of individual collisions is related to billions of molecules with different geometries, angels, and frequencies of vibration [54].

Researchers have used several methods based on the Arrhenius equation for determining the activation energy. The fraction of reaction is defined as:

$$
\alpha=\frac{m_{i}-m}{m_{i}-m_{f}}
$$

where $m_{i}$ is the initial mass of the solid reactant (iron oxide), $m$ is the actual mass of solid reactant at the time of $t$, and $m_{f}$ is the final mass of the solid reactant at the end of reaction or in other words, all of the solid mass that can react in the reaction. 
The rate equation for a gas-solid reaction is defined generally as:

$$
\frac{d \alpha}{d t}=k(T) \times f(\alpha)
$$

where $k(T)$ is the rate constant as a function of temperature, and $f(\alpha)$ is a function of the fraction of reaction that depends on the kinetics model. Using the Arrhenius equation:

$$
\begin{gathered}
\frac{d \alpha}{d t}=A \times \exp \left(-\frac{E_{a}}{R T}\right) \times f(\alpha) \\
\ln \left(\frac{\frac{d \alpha}{d t}}{f(\alpha)}\right)=-\frac{E_{a}}{R T}+\ln (A)
\end{gathered}
$$

By plotting the $\ln \left(\frac{\frac{d \alpha}{d t}}{f(\alpha)}\right)$ versus $\frac{1}{T}$ the activation energy can be determined from the slope of the line $[10,19,23,41,49,51,55-58]$ (Figure 17).

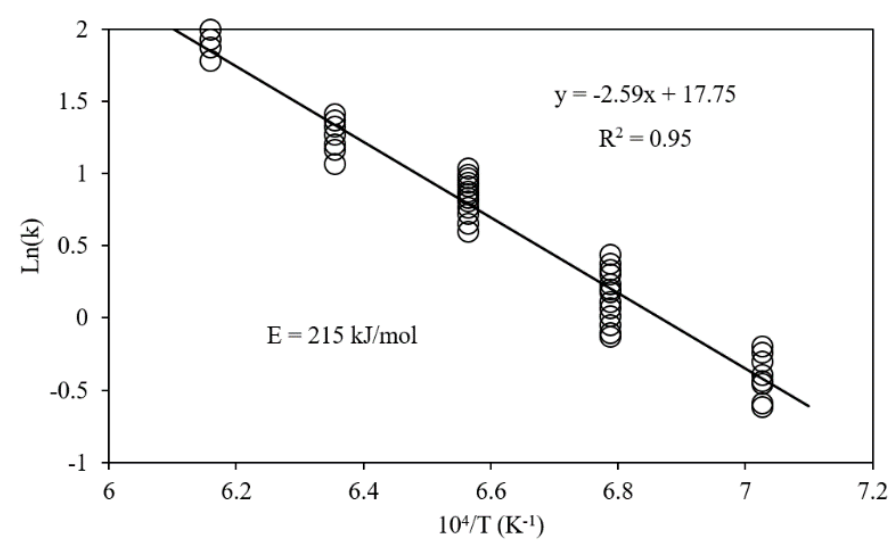

Figure 17. Arrhenius plot between Ln $k$ and $10^{4} / T$. ( $\mathrm{k}$ in atm $\left.\mathrm{at}^{-1} / \mathrm{s}\right)$. Points at each temperature represent data under different $\mathrm{H}_{2}$ partial pressures and reaction times [48] "modified".

Some researchers used the Kissinger method for calculating the activation energy [59,60]. In this method, the maximum rate of reaction is achieved when the derivation of the equation with respect to time is zero:

$$
\frac{d}{d t}\left(\frac{d \alpha}{d t}\right)=\frac{d}{d t}\left(A \times \exp \left(-\frac{E_{a}}{R T}\right) \times f(\alpha)\right)=0
$$

After derivation, Equation (14) is obtained:

$$
A \times \frac{E_{a}}{R T^{2}} \times \exp \left(-\frac{E_{a}}{R T}\right) \frac{d T}{d t} \times f(\alpha)+A \times \exp \left(-\frac{E_{a}}{R T}\right) \times \frac{d f(\alpha)}{d t}=0
$$

Using "Chain rule", Equation (15) can be expressed as:

$$
\frac{d f(\alpha)}{d t}=\frac{d f(\alpha)}{d \alpha} \times \frac{d \alpha}{d t}
$$

The $g(\alpha)$ and $\Phi$ can be defined as:

$$
\begin{aligned}
\frac{d \alpha}{d f(\alpha)} & =g(\alpha) \\
\frac{d T}{d t} & =\phi
\end{aligned}
$$


Using Equations (11) and (14)-(17), Equation (13) can be further rewritten as:

$$
\ln \left(\frac{\phi}{T_{m}^{2}}\right)=\ln \left(\frac{A R}{E_{a g} g(\alpha)}\right)-\frac{E_{a}}{R T_{m}}
$$

where $\Phi$ is the heating rate and $T_{m}$ is the temperature when the reaction rate is maximum. By plotting $\ln \left(\frac{\phi}{T_{m^{2}}}\right)$ versus $\frac{1}{T_{m}}$ the activation energy can be determined from the slope of the line (Figure 18) [61].

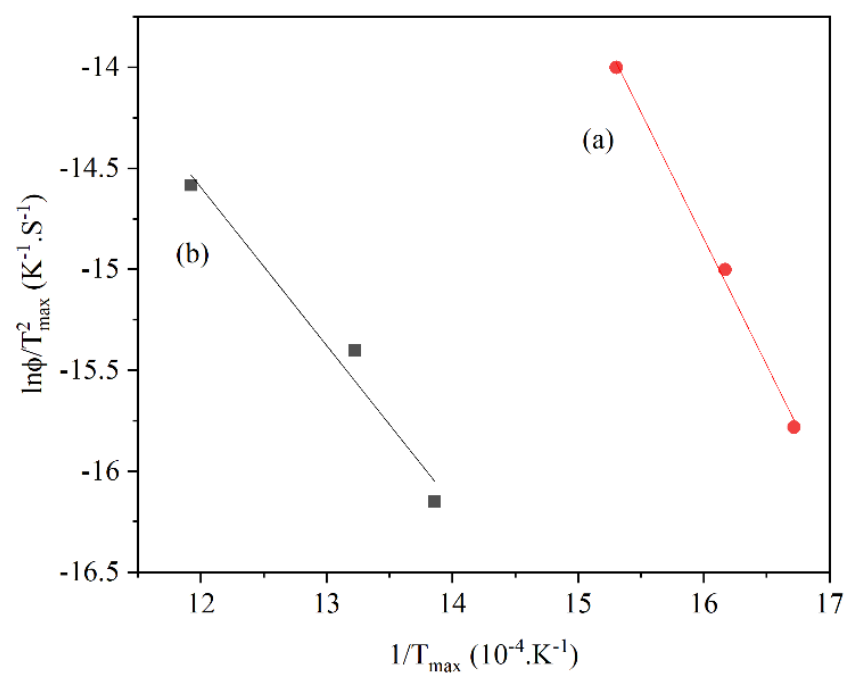

Figure 18. Temperature-programmed Arrhenius plots for the two-step reduction. (a) $\mathrm{Fe}_{2} \mathrm{O}_{3} \rightarrow \mathrm{Fe}_{3} \mathrm{O}_{4}$, (b) $\mathrm{Fe}_{3} \mathrm{O}_{4} \rightarrow \mathrm{Fe}[60]$ "modified".

The amounts of apparent activation energy determined in various studies related to the reduction of iron oxides to hydrogen are listed in Table 1. As it turns out, the activation energies have a wide range of values. This is because the value of activation energy depends on the chemical composition, physical properties of materials, temperature range, and process conditions. It is inferred from Table 1 that, the activation energy decreases by increasing the percentage of hydrogen in the reducing gas, which indicates the easier reduction of iron oxides by hydrogen than carbon monoxide. In addition, the activation energy for the reduction of natural magnetite to iron is higher than the reduction of magnetite, which has produced by the reduction of hematite. Furthermore, the activation energy is lower for the higher temperature ranges and some researchers reported a decrease in activation energy around a transition temperature that may be related to the changes in the kinetics controlling mechanism.

Table 1. The amounts of apparent activation energy related to the reduction of iron oxides by hydrogen.

\begin{tabular}{|c|c|c|c|}
\hline Reference & Reduction Reaction/Step & $E_{a}(k J / m o l)$ & Relevant Operating Conditions \\
\hline \multirow[t]{7}{*}{ [62] } & $\mathrm{Fe}_{2} \mathrm{O}_{3} \rightarrow \mathrm{Fe}$ & 57.1 & Pure $\mathrm{Fe}_{2} \mathrm{O}_{3}$ \\
\hline & $\mathrm{Fe}_{2} \mathrm{O}_{3} \rightarrow \mathrm{Fe}$ & 110.5 & $\mathrm{Fe}_{2} \mathrm{O}_{3}$ mixed with $\mathrm{MgO}$ \\
\hline & $\mathrm{Fe}_{2} \mathrm{O}_{3} \rightarrow \mathrm{Fe}$ & 108.4 & $\mathrm{Fe}_{2} \mathrm{O}_{3}$ mixed with $\mathrm{Al}_{2} \mathrm{O}_{3}$ \\
\hline & $\mathrm{Fe}_{2} \mathrm{O}_{3} \rightarrow \mathrm{Fe}$ & 108.4 & $\mathrm{Fe}_{2} \mathrm{O}_{3}$ mixed with $\mathrm{In}_{2} \mathrm{O}_{3}$ \\
\hline & $\mathrm{Fe}_{2} \mathrm{O}_{3} \rightarrow \mathrm{Fe}$ & 108.4 & $\mathrm{Fe}_{2} \mathrm{O}_{3}$ mixed with $\mathrm{Li}_{2} \mathrm{O}$ \\
\hline & $\mathrm{Fe}_{2} \mathrm{O}_{3} \rightarrow \mathrm{Fe}$ & 130.0 & $\mathrm{Fe}_{2} \mathrm{O}_{3}$ mixed with $\mathrm{TiO}_{2}$ \\
\hline & $\mathrm{Fe}_{2} \mathrm{O}_{3} \rightarrow \mathrm{Fe}$ & 89.9 & Hematite ore \\
\hline \multirow[t]{2}{*}[60]{} & $\mathrm{Fe}_{2} \mathrm{O}_{3} \rightarrow \mathrm{Fe}_{3} \mathrm{O}_{4}$ & 89.1 & $5 \% \mathrm{H}_{2}+95 \% \mathrm{~N}_{2}$ \\
\hline & $\mathrm{Fe}_{3} \mathrm{O}_{4} \rightarrow \mathrm{Fe}$ & 70.4 & $5 \% \mathrm{H}_{2}+95 \% \mathrm{~N}_{2}$ \\
\hline \multirow[t]{2}{*}{ [63] } & $\mathrm{Fe}_{2} \mathrm{O}_{3} \rightarrow \mathrm{Fe}$ & 51.0 & Hematite ore \\
\hline & $\mathrm{Fe}_{2} \mathrm{O}_{3} \rightarrow \mathrm{Fe}$ & 96.1 & Natural single crystals \\
\hline$[64]$ & $\mathrm{Fe}_{2} \mathrm{O}_{3} \rightarrow \mathrm{Fe}$ & $20-46$ & $\mathrm{Fe}_{2} \mathrm{O}_{3}$ nanopowder \\
\hline
\end{tabular}


Table 1. Cont.

\begin{tabular}{|c|c|c|c|}
\hline Reference & Reduction Reaction/Step & $\mathrm{E}_{\mathrm{a}}(\mathrm{kJ} / \mathrm{mol})$ & Relevant Operating Conditions \\
\hline$[65]$ & $\mathrm{Fe}_{2} \mathrm{O}_{3} \rightarrow \mathrm{Fe}$ & $15-20$ & $\mathrm{Fe}_{2} \mathrm{O}_{3} /$ metal Pellets \\
\hline \multirow[t]{4}{*}{ [58] } & $\mathrm{Fe}_{2} \mathrm{O}_{3} \rightarrow \mathrm{Fe}_{3} \mathrm{O}_{4}$ & 75.9 & \\
\hline & $\mathrm{Fe}_{2} \mathrm{O}_{3} \rightarrow \mathrm{Fe}_{3} \mathrm{O}_{4}$ & 94.8 & $10 \% \mathrm{H}_{2}+90 \% \mathrm{~N}_{2}$ \\
\hline & $\mathrm{Fe}_{3} \mathrm{O}_{4} \rightarrow \mathrm{Fe}$ & 88.0 & \\
\hline & $\mathrm{Fe}_{3} \mathrm{O}_{4} \rightarrow \mathrm{Fe}$ & 103.0 & $10 \% \mathrm{H}_{2}+90 \% \mathrm{~N}_{2}$ \\
\hline \multirow[t]{2}{*}[55]{} & $\mathrm{Fe}_{2} \mathrm{O}_{3} \rightarrow \mathrm{Fe}$ & 28.1 & $10 \% \mathrm{H}_{2}+90 \% \mathrm{~N}_{2}$ \\
\hline & $\mathrm{Fe}_{2} \mathrm{O}_{3} \rightarrow \mathrm{Fe}$ & 93.7 & $5.7 \% \mathrm{CO}+4.3 \% \mathrm{H}_{2}+90 \% \mathrm{~N}_{2}$ \\
\hline \multirow[t]{2}{*}[56]{} & $\mathrm{Fe}_{2} \mathrm{O}_{3} \rightarrow \mathrm{Fe}$ & 111 & Hematite pellet with biomass \\
\hline & $\mathrm{Fe}_{2} \mathrm{O}_{3} \rightarrow \mathrm{Fe}$ & 122 & Hematite pellet without biomass \\
\hline \multirow[t]{2}{*}{ [23] } & $\mathrm{Fe}_{3} \mathrm{O}_{4} \rightarrow \mathrm{FeO}$ & 47 & \\
\hline & $\mathrm{FeO} \rightarrow \mathrm{Fe}$ & 30 & \\
\hline \multirow[t]{3}{*}[66]{} & $\mathrm{Fe}_{3} \mathrm{O}_{4} \rightarrow \mathrm{Fe}$ & 200 & $227^{\circ} \mathrm{C}<\mathrm{T}<250^{\circ} \mathrm{C}$ \\
\hline & $\mathrm{Fe}_{3} \mathrm{O}_{4} \rightarrow \mathrm{Fe}$ & 71 & $250{ }^{\circ} \mathrm{C}<\mathrm{T}<390^{\circ} \mathrm{C}$ \\
\hline & $\mathrm{Fe}_{3} \mathrm{O}_{4} \rightarrow \mathrm{Fe}$ & 44 & $\mathrm{~T}>390^{\circ} \mathrm{C}$ \\
\hline \multirow[t]{2}{*}[67]{} & $\mathrm{Fe}_{3} \mathrm{O}_{4} \rightarrow \mathrm{Fe}$ (step) & $59-69$ & $5 \% \mathrm{H}_{2}+95 \% \mathrm{He}$ \\
\hline & $\mathrm{Fe}_{3} \mathrm{O}_{4} \rightarrow \mathrm{Fe}$ & $61-75$ & $5 \% \mathrm{H}_{2}+95 \% \mathrm{He}$ \\
\hline [19] & $\mathrm{Fe}_{3} \mathrm{O}_{4} \rightarrow \mathrm{FeO}$ & 13.5 & $5 \% \mathrm{H}_{2}+95 \% \mathrm{Ar}$ \\
\hline \multirow{4}{*}{ [57] } & $\mathrm{Fe}_{2} \mathrm{O}_{3} \rightarrow \mathrm{Fe}$ & 37.4 & $25 \% \mathrm{H}_{2}+75 \% \mathrm{CO}$ \\
\hline & $\mathrm{Fe}_{2} \mathrm{O}_{3} \rightarrow \mathrm{Fe}$ & 40.1 & $50 \% \mathrm{H}_{2}+50 \% \mathrm{CO}$ \\
\hline & $\mathrm{Fe}_{2} \mathrm{O}_{3} \rightarrow \mathrm{Fe}$ & 54.3 & $75 \% \mathrm{H}_{2}+25 \% \mathrm{CO}$ \\
\hline & $\mathrm{Fe}_{2} \mathrm{O}_{3} \rightarrow \mathrm{Fe}$ & 53.5 & $100 \% \mathrm{H}_{2}$ \\
\hline \multirow[t]{4}{*}{ [51] } & $\mathrm{Fe}_{2} \mathrm{O}_{3} \rightarrow \mathrm{Fe}$ & 50.9 & $5 \% \mathrm{H}_{2}+30 \% \mathrm{CO}+65 \% \mathrm{~N}_{2}$ \\
\hline & $\mathrm{Fe}_{2} \mathrm{O}_{3} \rightarrow \mathrm{Fe}$ & 36.3 & $10 \% \mathrm{H}_{2}+30 \% \mathrm{CO}+60 \% \mathrm{~N}_{2}$ \\
\hline & $\mathrm{Fe}_{2} \mathrm{O}_{3} \rightarrow \mathrm{Fe}$ & 35.8 & $15 \% \mathrm{H}_{2}+30 \% \mathrm{CO}+55 \% \mathrm{~N}_{2}$ \\
\hline & $\mathrm{Fe}_{2} \mathrm{O}_{3} \rightarrow \mathrm{Fe}$ & 30.4 & $20 \% \mathrm{H}_{2}+30 \% \mathrm{CO}+50 \% \mathrm{~N}_{2}$ \\
\hline \multirow[t]{3}{*}{ [25] } & $\mathrm{Fe}_{2} \mathrm{O}_{3} \rightarrow \mathrm{Fe}_{3} \mathrm{O}_{4}$ & 92.0 & \\
\hline & $\mathrm{Fe}_{3} \mathrm{O}_{4} \rightarrow \mathrm{FeO}$ & 71.1 & \\
\hline & $\mathrm{FeO} \rightarrow \mathrm{Fe}$ & 63.6 & \\
\hline [48] & $\mathrm{Fe}_{2} \mathrm{O}_{3} \rightarrow \mathrm{Fe}$ & 215 & \\
\hline \multirow[t]{3}{*}{ [36] } & $\mathrm{FeO} \rightarrow \mathrm{Fe}$ & 53.7 & $100 \% \mathrm{H}_{2}$ \\
\hline & $\mathrm{FeO} \rightarrow \mathrm{Fe}$ & 60.6 & $75 \% \mathrm{H}_{2}+25 \% \mathrm{CO}$ \\
\hline & $\mathrm{FeO} \rightarrow \mathrm{Fe}$ & 64.8 & $50 \% \mathrm{H}_{2}+50 \% \mathrm{CO}$ \\
\hline \multirow[t]{2}{*}{ [59] } & $\mathrm{Fe}_{2} \mathrm{O}_{3} \rightarrow \mathrm{Fe}_{3} \mathrm{O}_{4}$ & $105-120$ & $\mathrm{Fe}_{2} \mathrm{O}_{3}$ nanopowder \\
\hline & $\mathrm{Fe}_{3} \mathrm{O}_{4} \rightarrow \mathrm{Fe}$ & $55-45$ & $\mathrm{Fe}_{2} \mathrm{O}_{3}$ nanopowder \\
\hline
\end{tabular}

\subsection{Kinetics Controlling Models}

The summary of some research on the iron oxides reduction by hydrogen and the used kinetics models are provided in Table 2. As was mentioned earlier, the kinetics model depends on the reduction condition such as temperature, iron oxide type, particle size, etc. The table shows that although some researchers have chosen the nucleation models as the controller, chemical reaction at the interfaces and diffusion of hydrogen through the iron oxide particle are two common models among the related studies and it seems that the kinetics of iron ore reduction by hydrogen is mixed-control. Furthermore, it was asserted by most of the researchers that the rate-controlling step is the reduction of wüstite to iron when a dense shell of iron forms on the wüstite layer and the diffusion of hydrogen through this shell becomes difficult [17]. In addition, it should be observed that increasing the temperature improves the kinetics of reduction in both models, but its effect is more significant for diffusion. Hence, at high temperatures and especially at the early stages of the reduction, diffusion is not the rate controller $[23,26]$. 
Table 2. Kinetics models of the iron oxides reduction by hydrogen due to the condition.

\begin{tabular}{|c|c|c|}
\hline Reference & Kinetics Controller & Condition/Description \\
\hline [62] & topo chemical reaction & Pure $\mathrm{Fe}_{2} \mathrm{O}_{3}$ \\
\hline [60] & two-dimensional nucleation & reduction of hematite to magnetite \\
\hline [49] & diffusion through ash & \\
\hline & chemical reaction & \\
\hline [46] & chemical reaction & reduction of magnetite \\
\hline \multirow[t]{2}{*}{ [58] } & $\begin{array}{l}\text { Two- and three-dimensional } \\
\text { nucleation }\end{array}$ & $\mathrm{T}<420^{\circ} \mathrm{C}$ \\
\hline & chemical reaction & $\mathrm{T}>420{ }^{\circ} \mathrm{C}$ \\
\hline \multirow[t]{2}{*}{ [55] } & $\begin{array}{l}\text { Two-dimensional nucleation } \\
\text { and chemical reaction }\end{array}$ & initial stage \\
\hline & diffusion through ash & end of reaction \\
\hline [56] & chemical reaction & reduction of wüstite \\
\hline [23] & chemical reaction & \\
\hline [66] & diffusion & $\begin{array}{l}\text { reduction of magnetite at } \\
\text { low temperature }\end{array}$ \\
\hline [57] & $\begin{array}{l}\text { chemical reaction } \\
\text { diffusion through ash }\end{array}$ & \\
\hline$[51]$ & $\begin{array}{l}\text { chemical reaction } \\
\text { diffusion through ash }\end{array}$ & \\
\hline$[65]$ & $\begin{array}{l}\text { chemical reaction } \\
\text { diffusion through ash }\end{array}$ & $\begin{array}{l}\text { reduction of hematite to magnetite } \\
\text { reduction of magnetite to wüstite }\end{array}$ \\
\hline [36] & chemical reaction & reduction of wüstite to iron \\
\hline [59] & nucleation & reduction of hematite to magnetite \\
\hline [68] & nucleation & reduction of wüstite to iron \\
\hline [33] & $\begin{array}{l}\text { chemical reaction } \\
\text { chemical reaction }\end{array}$ & $\begin{array}{l}\text { reduction of hematite to magnetite } \\
\text { reduction of magnetite to wüstite }\end{array}$ \\
\hline [69] & $\begin{array}{l}\text { diffusion through ash } \\
\text { chemical reaction } \\
\text { diffusion through ash }\end{array}$ & reduction of wüstite to iron \\
\hline [37] & $\begin{array}{l}\text { diffusion through film } \\
\text { diffusion through ash }\end{array}$ & \\
\hline [25] & diffusion through ash & \\
\hline \multirow[t]{2}{*}{ [70] } & nucleation & initial stage \\
\hline & $\begin{array}{l}\text { chemical reaction and } \\
\text { diffusion through ash }\end{array}$ & end of reaction \\
\hline [48] & nucleation & initial stage \\
\hline$[50]$ & $\begin{array}{l}\text { diffusion through film } \\
\text { chemical reaction }\end{array}$ & $\begin{array}{l}\text { reduction of hematite to magnetite } \\
\text { reduction of magnetite to wüstite }\end{array}$ \\
\hline \multirow{4}{*}{$\begin{array}{l}{[28]} \\
{[71]} \\
{[72]}\end{array}$} & diffusion through ash & reduction of wüstite to iron \\
\hline & diffusion through ash & \\
\hline & chemical reaction & \\
\hline & diffusion through ash & \\
\hline
\end{tabular}

\section{Conclusions}

In order to reduce the amount of $\mathrm{CO}_{2}$ pollution in the iron and steel industry, it is crucial to investigate new methods of iron oxide reduction. Among all these techniques, using hydrogen as a reducing agent is receiving much attention. In addition, it is necessary to study the exact material and energy consumption by investigating the kinetics of the reduction reactions. These solid-gas reactions are complex and can vary due to the working temperature, gas atmosphere, chemical composition, etc. The mechanisms that control the kinetics of reduction are the diffusion of $\mathrm{H}_{2} / \mathrm{H}_{2} \mathrm{O}$ through the gas film layer, diffusion of $\mathrm{H}_{2} / \mathrm{H}_{2} \mathrm{O}$ through the ash layer, and chemical reaction. For the high gas velocity, film resistance can be ignored. It was approved by some researchers that nucleation also can be considered as a controlling mechanism at the early stages of the reduction and at low temperatures. 
Moreover, the parameters such as temperature, porosity, mineralogy, etc. can play a vital role in order to determine the kinetics of hydrogen reduction precisely. The following conclusions can be made for each parameter according to this literature review:

- Effect of Temperature: Due to the Arrhenius equation, by increasing the temperature, the rate of reduction will increase exponentially. At temperatures above $590{ }^{\circ} \mathrm{C}$, the effect of temperature on the reduction of $\mathrm{Fe}_{2} \mathrm{O}_{3}$ to $\mathrm{Fe}_{3} \mathrm{O}_{4}$ and reduction of $\mathrm{FeO}$ to $\mathrm{Fe}$ is negligible, but for the reduction of $\mathrm{Fe}_{3} \mathrm{O}_{4}$ to $\mathrm{FeO}$ it is considerable.

- Effect of $\mathrm{H}_{2} / \mathrm{CO}$ ratio: The reaction rate would increase with the higher hydrogen content at temperatures above $1000{ }^{\circ} \mathrm{C}$. Additionally, $\mathrm{H}_{2} / \mathrm{CO}$ proportion has the most beneficial effect on the reduction rate when being 1.6, and the higher ratios effect is negligible.

- Effect of hydrogen flow rate: Higher inlet flow rate causes higher steam generation at the early stages of the reaction and at the later stages, the effect is minor. Additionally, there is a critical gas velocity below which gas flow rate controls the rate of the reaction.

- Effect of iron ore mineralogy: Because of the hard and dense shell of magnetite in comparison with hematite, magnetite has lower diffusion. Thus, the reduction of hematite by hydrogen is faster than the reduction of magnetite, especially at higher temperatures.

- Effect of particle size: As the size of the particle decreases the specific area increases, therefore the reduction rate enlarges because the reaction starts from the surface. Furthermore, the smaller particle size leads to a shorter distance that gas has to pass to reach inner layers. However, as the particle size shrinks, the chance of agglomeration will increase and as a result, the specific area decreases.

- Effect of impurities: The effect of impurities can be assumed as reduction by $\mathrm{H}_{2}$ and $\mathrm{CO}$. Impurities such as $\mathrm{CaO}, \mathrm{SiO}_{2}$, and $\mathrm{MgO}$ and alumina forms can lead to the formation of micro-cracks that promote the reduction of wüstite. Contrarily, some impurities such as $\mathrm{Al}_{2} \mathrm{O}_{3}$ and $\mathrm{MgO}$ decrease the rate of magnetite reduction.

Activation energy definition is the minimum energy that is required to perform a chemical reaction. Lower activation energy shows easier reduction of iron oxides. For instance, the activation energy decreases by increasing the percentage of hydrogen in the reducing gas. In fact, activation energy is dependent on chemical composition, physical properties of materials, temperature range, and process conditions. As a result, there is a wide range of values for the activation energy of reactions. The activation energy of natural magnetite to iron is higher than the reduction of the other forms of iron oxide.

Kinetics models depend on different parameters of reduction such as temperature, iron oxide type, particle size, etc. commonly, chemical reactions at the interfaces and the diffusion of hydrogen through the iron oxide particle are used as kinetics models. Through the reduction of wüstite to iron an iron shell covers the surface of the sample and makes the diffusion hard. Thus, wüstite reduction is the rate-controlling and slowest step.

Author Contributions: Conceptualization, A.H. and N.N.; investigation, A.H. and N.N.; resources, A.H. and N.N.; data curation, A.H.; writing-original draft preparation, A.H. and N.N.; writingreview and editing, A.H. and N.N.; visualization, A.H. and N.N.; supervision, M.I. and T.F.; project administration, M.I. and T.F; funding acquisition, T.F. All authors have read and agreed to the published version of the manuscript.

Funding: This research was funded by Business Finland as a part of the Towards Fossil-free Steel (FFS) research program, grant number $45774 / 31 / 2020$. This research is a part of the CLEAN2STEEL project that benefits from the financial and strategic support of the Kvantum Institute.

Institutional Review Board Statement: Not applicable.

Informed Consent Statement: Not applicable.

Data Availability Statement: No new data were created or analyzed in this study. Data sharing is not applicable to this article. 
Acknowledgments: The authors of this study express their gratitude to the Association of Finnish Steel and Metal Producers and Kvantum Institute for their support.

Conflicts of Interest: The authors declare no conflict of interest.

\section{References}

1. Holappa, L. A general vision for reduction of energy consumption and $\mathrm{CO}_{2}$ emissions from the steel industry. Metals 2020, 10, 1117. [CrossRef]

2. IEA. Iron and Steel; IEA: Paris, France, 2020.

3. Bitsianes, G.; Joseph, T.L. Topochemical Aspects of Iron Ore Reduction. JOM 1955, 7, 639-645. [CrossRef]

4. Tsay, Q.; Ray, W.; Szekley, J. The modelling of hematite reduction with hydrogen plus carbon monoxide mixtures: Part I. behavior of single pellets. AlChE J. 1976, 22, 1064-1072. [CrossRef]

5. Spreitzer, D.; Schenk, J. Reduction of Iron Oxides with Hydrogen-A Review. Steel Res. Int. 2019, 90, 1900108. [CrossRef]

6. Rechberger, K.; Spanlang, A.; Sasiain Conde, A.; Wolfmeir, H.; Harris, C. Green Hydrogen-Based Direct Reduction for Low-Carbon Steelmaking. Steel Res. Int. 2020, 91, 1-10. [CrossRef]

7. Cuéllar-Franca, R.M.; Azapagic, A. Carbon capture, storage and utilisation technologies: A critical analysis and comparison of their life cycle environmental impacts. J. CO2 Util. 2015, 9, 82-102. [CrossRef]

8. Birat, J.-P. 16-Carbon dioxide $\left(\mathrm{CO}_{2}\right)$ capture and storage technology in the iron and steel industry. In Developments and Innovation in Carbon Dioxide $\left(\mathrm{CO}_{2}\right)$ Capture and Storage Technology; Woodhead Publishing Series in Energy; Maroto-Valer, M., Ed.; Woodhead Publishing: Sawston, UK, 2010; Volume 1, pp. 492-521, ISBN 978-1-84569-533-0.

9. Sjoberg Elf, J.; Espinosa, K.W. Carbon Capture and Utilisation in the Steel Industry. A Study Exploring the Integration of Carbon Capture Technology and High-Temperature CO-Electrolysis of $\mathrm{CO}_{2}$ and $\mathrm{H}_{2} \mathrm{O}$ to Produce Synthetic Gas; Kth Royal Institute of Technology: Stockolm, Sweden, 2017.

10. Pérez-Fortes, M.; Moya, J.A.; Vatopoulos, K.; Tzimas, E. $\mathrm{CO}_{2}$ capture and utilization in cement and iron and steel industries Energy Procedia 2014, 63, 6534-6543. [CrossRef]

11. Suopajärvi, H.; Pongrácz, E.; Fabritius, T. The potential of using biomass-based reducing agents in the blast furnace: A review of thermochemical conversion technologies and assessments related to sustainability. Renew. Sustain. Energy Rev. 2013, 25, 511-528. [CrossRef]

12. Hammerschmid, M.; Müller, S.; Fuchs, J.; Hofbauer, H. Evaluation of biomass-based production of below zero emission reducing gas for the iron and steel industry. Biomass Convers. Biorefinery 2021, 11, 169-187. [CrossRef]

13. Gao, Y.M.; Wang, B.; Wang, S.B.; Peng, S. Study on electrolytic reduction with controlled oxygen flow for iron from molten oxide slag containing FeO. J. Min. Metall. Sect. B Metall. 2013, 49, 49-55. [CrossRef]

14. Allanore, A.; Lavelaine, H.; Valentin, G.; Birat, J.P.; Lapicque, F. Iron Metal Production by Bulk Electrolysis of Iron Ore Particles in Aqueous Media. J. Electrochem. Soc. 2008, 155, E125. [CrossRef]

15. Cavaliere, P. Electrolysis of Iron Ores: Most Efficient Technologies for Greenhouse Emissions Abatement. In Clean Ironmaking and Steelmaking Processes: Efficient Technologies for Greenhouse Emissions Abatement; Springer International Publishing: Cham, Switzerland, 2019; pp. 555-576, ISBN 978-3-030-21209-4.

16. Lepage, T.; Kammoun, M.; Schmetz, Q.; Richel, A. Biomass-to-hydrogen: A review of main routes production, processes evaluation and techno-economical assessment. Biomass Bioenergy 2021, 144, 105920. [CrossRef]

17. Patisson, F.; Mirgaux, O. Hydrogen ironmaking: How it works. Metals 2020, 10, 922. [CrossRef]

18. Bessières, J.; Bessières, A.; Heizmann, J.J. Iron oxide reduction kinetics by hydrogen. Int. J. Hydrogen Energy 1980, 5, 585-595. [CrossRef]

19. Hou, B.; Zhang, H.; Li, H.; Zhu, Q. Study on kinetics of iron oxide reduction by hydrogen. Chin. J. Chem. Eng. 2012, 20, 10-17. [CrossRef]

20. McKewan, W.M. Kinetics of iron oxide reduction. Trans. Am. Inst. Min. Metall. Eng. 1960, 218, 2-6.

21. Levenspiel, O. Chemical Reaction Engineering, 3rd ed.; Wiley: Hoboken, NJ, USA, 1999; ISBN 9780471530169.

22. Von Bogdandy, L.; Engell, H.J. The Reduction of Iron Ores: Scientific Basis and Technology, 1st ed.; Springer-Verlag: Berlin/Heidelberg, Germany, 1971; ISBN 9783662104002.

23. Barde, A.A.; Klausner, J.F.; Mei, R. Solid state reaction kinetics of iron oxide reduction using hydrogen as a reducing agent. Int. J. Hydrogen Energy 2016, 41, 10103-10119. [CrossRef]

24. Valipour, M.S.; Motamed Hashemi, M.Y.; Saboohi, Y. Mathematical modeling of the reaction in an iron ore pellet using a mixture of hydrogen, water vapor, carbon monoxide and carbon dioxide: An isothermal study. Adv. Powder Technol. 2006, 17, 277-295. [CrossRef]

25. Tsay, Q.T.; Ray, W.H.; Szekely, J. The modeling of hematite reduction with hydrogen plus carbon monoxide mixtures: Part II. The direct reduction process in a shaft furnace arrangement. AIChE J. 1976, 22, 1072-1079. [CrossRef]

26. Wagner, D.; Devisme, O.; Patisson, F.; Ablitzer, D. A Laboratory Study of the Reduction of Iron Oxides by Hydrogen. In Proceedings of the 2006 TMS Fall Extraction and Processing Division: Sohn International Symposium, San Diego, CA, USA, 27-31 August 2006; Volume 2, pp. 111-120.

27. Choi, M.E.; Sohn, H.Y. Development of green suspension ironmaking technology based on hydrogen reduction of iron oxide concentrate: Rate measurements. Ironmak. Steelmak. 2010, 37, 81-88. [CrossRef] 
28. Fruehan, R.J.; Li, Y.; Brabie, L.; Kim, E.J. Final stage of reduction of iron ores by hydrogen. Scand. J. Metall. 2005, 34, 205-212. [CrossRef]

29. Steffen, R.; Tacke, K.H. Hydrogen for the reduction of iron ores-State of the art and future aspects. Stahl Eisen 2004, 124, 45-52.

30. Yang, Y.; Raipala, K.; Holappa, L. Ironmaking; Elsevier Ltd.: Amsterdam, The Netherlands, 2014; Volume 3, ISBN 9780080969886.

31. Kemppainen, A.; Mattila, O.; Heikkinen, E.P.; Paananen, T.; Fabritius, T. Effect of $\mathrm{H}_{2}-\mathrm{H}_{2} \mathrm{O}$ on the reduction of olivine pellets in CO-CO 2 gas. ISIJ Int. 2012, 52, 1973-1978. [CrossRef]

32. Zuo, H.B.; Wang, C.; Dong, J.J.; Jiao, K.X.; Xu, R.S. Reduction kinetics of iron oxide pellets with $\mathrm{H}_{2}$ and CO mixtures. Int. J. Miner. Metall. Mater. 2015, 22, 688-696. [CrossRef]

33. Yi, L.; Huang, Z.; Peng, H.; Jiang, T. Action rules of $\mathrm{H}_{2}$ and $\mathrm{CO}$ in gas-based direct reduction of iron ore pellets. J. Cent. South. Univ. 2012, 19, 2291-2296. [CrossRef]

34. Abdelrahim, A.; Iljana, M.; Omran, M.; Vuolio, T.; Bartusch, H.; Fabritius, T. Influence of $\mathrm{H}_{2}-\mathrm{H}_{2} \mathrm{O}$ content on the reduction of acid iron ore pellets in a CO- $\mathrm{CO}_{2}-\mathrm{N}_{2}$ reducing atmosphere. ISIJ Int. 2020, 60, 2206-2217. [CrossRef]

35. Abu Tahari, M.N.; Salleh, F.; Tengku Saharuddin, T.S.; Samsuri, A.; Samidin, S.; Yarmo, M.A. Influence of hydrogen and carbon monoxide on reduction behavior of iron oxide at high temperature: Effect on reduction gas concentrations. Int. J. Hydrogen Energy 2021, 46, 24791-24805. [CrossRef]

36. El-Geassy, A.H.A. Rate Controlling Step in the Reduction of Iron Oxides; Kinetics and Mechanism of Wüstite-Iron Step in $\mathrm{H}_{2}$, $\mathrm{CO}$ and $\mathrm{H}_{2}$ /CO Gas Mixtures. IOP Conf. Ser. Mater. Sci. Eng. 2017, 229, 1-10. [CrossRef]

37. Kawasaki, E.; Sanscrainte, J.; Walsh, T.J. Kinetics of reduction of iron oxide with carbon monoxide and hydrogen. AIChE J. 1962, 8 , 48-52. [CrossRef]

38. Kuila, S.K.; Chatterjee, R.; Ghosh, D. Kinetics of hydrogen reduction of magnetite ore fines. Int. J. Hydrogen Energy 2016, 41, 9256-9266. [CrossRef]

39. Ohmi, M.; Usui, T. Improved Theory on the Rate of Reduction of Single Particles and Fixed Bed of Iron Oxide Pellets With Hydrogen. Trans. Iron Steel Inst. Jpn. 1982, 22, 66-74. [CrossRef]

40. Ohmi, M.; Usui, T.; Naito, M.; Minamide, Y. Experimental Study of the Resistance duo to the Rate of Gas Flow on the Hydrogen Reduction of an Iron Oxide Pellet. Tetsu-to-Hangane 1981, 67, 1943-1951. [CrossRef]

41. Edstrom, J.O. The mechanism of reduction of iron oxides. J. Iron Steel Inst. 1953, 175, 289.

42. Rau, M.F.; Rieck, D.; Evans, J.W. Investigation of iron oxide reduction by TEM. Metall. Trans. B 1987, 18, 257-278. [CrossRef]

43. Bogdandy, V.L.; Schulz, H.P.; Wiirzner, B.; Stranski, I.N.; von Bogdandy, L.; Schulz, H.P.; Würzner, B.; Stranski, I.N. Der Mechanismus der Reduktion von porigen Eisenerzen durch Wasserstoff. Arch. Eisenhüttenwes. 1963, 34, 401-409. [CrossRef]

44. Heikkilä, A.; Iljana, M.; Bartusch, H.; Fabritius, T. Reduction of Iron Ore Pellets, Sinter, and Lump Ore under Simulated Blast Furnace Conditions. Steel Res. Int. 2020, 91, 2000047. [CrossRef]

45. Jozwiak, W.K.; Kaczmarek, E.; Maniecki, T.P.; Ignaczak, W.; Maniukiewicz, W. Reduction behavior of iron oxides in hydrogen and carbon monoxide atmospheres. Appl. Catal. A Gen. 2007, 326, 17-27. [CrossRef]

46. Zhang, A.; Monaghan, B.J.; Longbottom, R.J.; Nusheh, M.; Bumby, C.W. Reduction Kinetics of Oxidized New Zealand Ironsand Pellets in $\mathrm{H}_{2}$ at Temperatures up to $1443 \mathrm{~K}$. Metall. Mater. Trans. B Process. Metall. Mater. Process. Sci. 2020, 51, 492-504. [CrossRef]

47. Teplov, O.A. Kinetics of the low-temperature hydrogen reduction of magnetite concentrates. Russ. Metall. 2012, $2012,8-21$. [CrossRef]

48. Chen, F.; Mohassab, Y.; Jiang, T.; Sohn, H.Y. Hydrogen Reduction Kinetics of Hematite Concentrate Particles Relevant to a Novel Flash Ironmaking Process. Metall. Mater. Trans. B 2015, 46, 1133-1145. [CrossRef]

49. Turkdogan, E.T.; Vinters, J.V. Gaseous reduction of iron oxides: Part, I. Reduction of hematite in hydrogen. Metall. Mater. Trans. B 1971, 2, 3175-3188. [CrossRef]

50. Corbari, R.; Fruehan, R.J. Reduction of iron oxide fines to wustite with $\mathrm{CO} / \mathrm{CO}_{2}$ gas of low reducing potential. Metall. Mater. Trans. B 2010, 41, 318-329. [CrossRef]

51. Qie, Y.; Lyu, Q.; Liu, X.; Li, J.; Lan, C.; Liu, X. Effect of hydrogen addition on reduction behavior of iron oxides in gas-injection blast furnace. ISIJ Int. 2017, 57, 404-417. [CrossRef]

52. Kapelyushin, Y.; Xing, X.; Zhang, J.; Jeong, S.; Sasaki, Y.; Ostrovski, O. Effect of Alumina on the Gaseous Reduction of Magnetite in $\mathrm{CO} / \mathrm{CO}_{2}$ Gas Mixtures. Metall. Mater. Trans. B Process. Metall. Mater. Process. Sci. 2015, 46, 1175-1185. [CrossRef]

53. Paananen, T.; Kinnunen, K. EFfect of $\mathrm{TiO}_{2}$-content on Reduction of Iron Ore Agglomerates. Steel Res. Int. 2009, 80, 408-414. [CrossRef]

54. Espenson, J.H. Chemical Kinetics and Reaction Mechanisms, 2nd ed.; Advanced Chemistry Series; McGraw-Hill: New York, NY, USA, 1995; ISBN 9780070202603.

55. Piotrowski, K.; Mondal, K.; Lorethova, H.; Stonawski, L.; Szymański, T.; Wiltowski, T. Effect of gas composition on the kinetics of iron oxide reduction in a hydrogen production process. Int. J. Hydrogen Energy 2005, 30, 1543-1554. [CrossRef]

56. Guo, D.; Hu, M.; Pu, C.; Xiao, B.; Hu, Z.; Liu, S.; Wang, X.; Zhu, X. Kinetics and mechanisms of direct reduction of iron ore-biomass composite pellets with hydrogen gas. Int. J. Hydrogen Energy 2015, 40, 4733-4740. [CrossRef]

57. El-Geassy, A.A.; Shehata, K.A.; Ezz, S.Y. Mechanism of Iron Oxide Reduction With Hydrogen/Carbon Monoxide Mixtures. Trans. Iron Steel Inst. Jpn. 1977, 17, 629-635. [CrossRef]

58. Pineau, A.; Kanari, N.; Gaballah, I. Kinetics of reduction of iron oxides by $\mathrm{H}_{2}$. Part I: Low temperature reduction of hematite. Thermochim. Acta 2006, 447, 89-100. [CrossRef] 
59. Manchili, S.K.; Wendel, J.; Hryha, E.; Nyborg, L. Analysis of iron oxide reduction kinetics in the nanometric scale using hydrogen. Nanomaterials 2020, 10, 1276. [CrossRef]

60. Lin, H.Y.; Chen, Y.W.; Li, C. The mechanism of reduction of iron oxide by hydrogen. Thermochim. Acta 2003, 400, 61-67. [CrossRef]

61. Kissinger, H.E. Variation of Peak Temperature With Heating Rate in Differential Thermal Analysis. J. Res. Natl. Bur. Stand. 1956, 57, 218-221. [CrossRef]

62. Sastri, M.V.C.; Viswanath, R.P.; Viswanathan, B. Studies on the reduction of iron oxide with hydrogen. Int. J. Hydrogen Energy 1982, 7, 951-955. [CrossRef]

63. Gray, N.B.; Henderson, J. Hydrogen reduction of dense hematites. AIME Met. Soc. Trans. 1966, 236, $1213-1217$.

64. Jung, S.S.; Lee, J.S. In-situ kinetic study of hydrogen reduction of $\mathrm{Fe}_{2} \mathrm{O}_{3}$ for the production of Fe nanopowder. Mater. Trans. 2009, 50, 2270-2276. [CrossRef]

65. Sohn, I.; Jung, S.M. Effect of metal additions to the reduction of iron oxide composite pellets with hydrogen at moderate temperatures. Steel Res. Int. 2011, 82, 1345-1354. [CrossRef]

66. Pineau, A.; Kanari, N.; Gaballah, I. Kinetics of reduction of iron oxides by $\mathrm{H}_{2}$. Part II. Low temperature reduction of magnetite. Thermochim. Acta 2007, 456, 75-88. [CrossRef]

67. Tiernan, M.J.; Barnes, P.A.; Parkes, G.M.B. Reduction of iron oxide catalysts: The investigation of kinetic parameters using rate perturbation and linear heating thermoanalytical techniques. J. Phys. Chem. B 2001, 105, 220-228. [CrossRef]

68. Kim, S.H.; Zhang, X.; Ma, Y.; Souza Filho, I.R.; Schweinar, K.; Angenendt, K.; Vogel, D.; Stephenson, L.T.; El-Zoka, A.A.; Mianroodi, J.R.; et al. Influence of microstructure and atomic-scale chemistry on the direct reduction of iron ore with hydrogen at $700{ }^{\circ}$ C. Acta Mater. 2021, 212, 116933. [CrossRef]

69. Bonalde, A.; Henriquez, A.; Manrique, M. Kinetic analysis of the iron oxide reduction using hydrogen-carbon monoxide mixtures as reducing agent. ISIJ Int. 2005, 45, 1255-1260. [CrossRef]

70. Sohn, I.; Fruehan, R.J. The reduction of iron oxides by volatiles in a rotary hearth furnace process: Part, I. The role and kinetics of volatile reduction. Metall. Mater. Trans. B 2005, 36, 605-612. [CrossRef]

71. Gaballah, N.M.; Zikry, A.F.; Khalifa, M.G.; Farag, A.B.; El-Hussiny, N.A.; Shalabi, M.E.H. Production of Iron from Mill Scale Industrial Waste via Hydrogen. Open, J. Inorg. Non Met. Mater. 2013, 3, 23-28. [CrossRef]

72. Kazemi, M.; Pour, M.S.; Sichen, D. Experimental and Modeling Study on Reduction of Hematite Pellets by Hydrogen Gas. Metall. Mater. Trans. B Process. Metall. Mater. Process. Sci. 2017, 48, 1114-1122. [CrossRef] 